\title{
The Use of Artificial Intelligence in the Field of Justice
}

\author{
Wilfried Bernhardt $<$ bernhardt-wi@t-online.de> \\ LEIPZIG, Germany
}

\section{Abstract}

The expectations on the judiciary remain high. In particular, the judiciary is expected to use modern IT in a manner like institutions in civil society. In addition, the situation is exacerbated by the fact that large platforms operated by the private sector have managed to use data to bring enormous new volumes of cases into the court system. Debt collection agencies send AI enabled automated filings of cases against people for debt to the courts. Thus, AI tools are leading to a flood of cases into the courts, calling for the courts to also use the tools to manage this volume of applications and automatically evaluate the cases received. And finally, the pressure is also growing due to competition from private arbitration courts and mediation bodies, online dispute resolution platforms and automated decision-making, which can produce much faster decisions than the courts due to intensive AI use. If one tries to catalog the AI under consideration for the judiciary, three main categories classification/analysis, translation/anonymization and interaction can be considered.

For example, AI can help to structure incoming documents and assign them to relevant areas of law and responsible judges, connections between different documents can be found or essential factual or legal aspects can be tracked down to provide essential insights for the court to prepare civil law decisions or to categorize crimes. AI can also help with machine translation and anonymization of court judgments. AI-powered chatbots can help citizens seeking legal protection. Although AI can assist judges in their work in a variety of ways, it is very doubtful whether AI can be used to make fully automated judicial decisions. Several principles of fundamental and human rights as well as the rule of law oppose a robot judge insofar as it removes judicial decisions from human control. But prudence is also called for when judges rely on AI-supported proposals in making their decisions. 


\section{Keywords:}

Artificial Intelligence judiciary, automated filings, private arbitration courts, online dispute resolution platforms, faster decisions, Legal Tech 3.0, prosecution authorities, structure incoming documents, information Retrieval, data extraction, automated analysis, statistical evaluation, legal aspects, prepare civil law decisions, categorize criminals, machine translation, anonymization of court judgments, detect child pornography, predicting the outcome of proceedings, machine learning AI, AI-powered chatbots, effective legal protection, fully automated judicial decisions, robot judge, fundamental rights, human rights, right to human dignity, protection of personal data, principle of non-discrimination, principle of the natural and independent judge, right to the legal judge, transparency principle, fair trial, principle of the right to be heard, trustworthy AI, certification systems, European AI regulation, risk-based approach, human control, AI-supported decision.

\section{Introduction}

The use of artificial intelligence (AI) has become widespread in many areas of the economy, and to some extend also in the administration. Some countries have taken the first steps to use AI in the area of justice. ${ }^{1}$ It is therefore worth examining how information technology, in particular the use of artificial intelligence make judicial work more user-friendly and efficient without disregarding fundamental constitutional principles and values.

\section{Definition of $A I$}

There is no uniform definition of AI. ${ }^{2}$ In the glossary of the Ethics Guidelines for trustworthy AI of the High Level Expert Group on Artificial Intel-

1 Jenny Gesley, 'Comparative Summary', Law Library of Congress (ed) Regulation of Artificial Intelligence in Selected Jurisdictions (January 2019) $1<$ https://www.loc.gov /law/help/artificial-intelligence/regulation-artificial-intelligence.pdf $>$ accessed 24 June 2021 .

2 Isabelle Biallaß, 'Legal Tech und künstliche Intelligenz' in Ory and Weth (ed), jurisPK-ERV vol 1, $1^{\text {st }}$ edition, chapter 8, status 28 August 2020, para 206. 
ligence $(\mathrm{AI})^{3}$ set up by the EU Commission, the following definition is used: „Artificial intelligence (AI) refers to systems designed by humans that, given a complex goal, act in the physical or digital world by perceiving their environment, interpreting the collected structured or unstructured data, reasoning on the knowledge derived from this data and deciding the best action(s) to take (according to pre-defined parameters) to achieve the given goal. AI systems can also be designed to learn to adapt their behavior by analyzing how the environment is affected by their previous actions". The definition in Art. 3 of the EU Commission's proposal for an AI Regulation ${ }^{4}$ is: „'artificial intelligence system' (AI system) means software that is developed with one or more of the techniques and approaches listed in Annex I and can, for a given set of human-defined objectives, generate outputs such as content, predictions, recommendations, or decisions influencing the environments they interact with". And also important the definition of the Commissioner for Human Rights ${ }^{5}$ : "An AI system is a machine-based system that makes recommendations, predictions or decisions for a given set of objectives. It does so by: (i) utilising machine and/or humanbased inputs to perceive real and/or virtual environments; (ii) abstracting such perceptions into models .anually or automatically; and (iii) deriving outcomes from these models, whether by human or automated means, in the form of recommendations, predictions or decisions."

\section{Stages of development of IT support for the judiciary}

IT support for the judiciary and communication with users of the judiciary ("E-JUSTICE") can look back on a history of more than twenty years also for example in Germany. Machine-readable data has long played an

$3<$ https://ec.europa.eu/digital-single-market/en/news/draft-ethics-guidelines-trustwor thy-ai $>$ accessed 30 May 2021.

4 COM (2021) 206 final <https://digital-strategy.ec.europa.eu/en/library/proposal-r egulation-laying-down-harmonised-rules-artificial-intelligence $>$ accessed 30 May 2021.

5 Council of Europe Commissioner for Human Rights: Recommendation Unboxing Artificial Intelligence: 10 steps to protect Human Rights (2019) <https://rm.coe.int/un boxing-artificial-intelligence-10-steps-to-protect-human-rights-reco/1680946e64> accessed 31 May2021. 
important role in this. From today's perspective, IT support in the judiciary or the legal profession is often divided into three groups ${ }^{6}$ :

"Legal Tech 1.o" refers to simple programs that facilitate the daily work of lawyers, such as legal databases or programs for document management and organization. It empowers the human players within the current system with computer assisted legal research, document production and case or customer management systems that store information. In Germany, legal online publishers such as Juris, founded in 1985, play an important role. Today, there are several online legal databases, some of them international. A convenient search in case law and literature, a linking of essays and online books with court decisions characterize legal online publishers today. Then, however, many courts also use programs that calculate, for example, obligations to pay alimony or pension equalization, the question of legal aid, or attorney and court fees. In Australia, the AI system "Split-Up" supports family court judges in divorce disputes: It identifies the parties' assets to be divided and based on a calculation, suggests a percentage that the respective party should receive. Legal Tech 2.0 refers to more complex programs that perform narrowly defined steps independently, such as the automated creation of legal documents (for example statements of claim) on the basis of predefined patterns and rules. Legal Tech 2.0 replaces an increasing number of human players. Automated order for payment procedures also belong to this category. Twenty years ago, it was already possible to transmit a German application for a payment order to the courts electronically. Since 2008, for example, lawyers have been obliged to send them electronically. The further processing of the procedure before the courts is also carried out electronically, even if the Rechtspfleger (legal officers) are still officially involved in the individual steps. The machine checks compliance with the formal legal requirements for the applications. It generates a corresponding payment order. However, the machine itself does not learn anything new; it does not check substantive legal and evidentiary issues. The machine does not decide whether the applicant is entitled to the claim. A similar situation applies to the European order for payment procedure. In this procedure, creditors can assert their uncontested civil and commercial claims according to a uniform procedure based on electronic standard forms across borders and with automated translations into all official EU languages.

6 The classification can be found at Oliver R. Goodenough, 'Legal Technology 3.0' (HuffPost, 6 April 2015) <https://www.huffpost.com/entry/legal-technology-30_b_ 6603658> accessed 29 May 2021. 
While the process is largely automated, ultimate responsibility for the outcome remains with a natural person of the court. A fully electronic procedure ranging from the electronic submission of applications to fully automated decision without human intervention have not yet been provided for by the German legal system. However, there are corresponding projects in other European countries: In Estonia, for example, there are plans to have an AI-based program autonomously decide on civil contract disputes with a value in dispute of less than 7000 euros, although these decisions can then be appealed to a human judge. ${ }^{7}$ In this context, the term "robot judge" is then used.

In contrast, in administrative procedures, a basis for the regulation of an automatic administrative act has existed since Jan. 1, 2017 (Section 35a of the German Administrative Procedure Act) and allows the administration to issue an administrative act entirely through automatic devices (without a human decision maker) provided this is permitted by another legal provision and neither discretionary.

Finally, Legal Tech 3.0 refers to highly complex programs in the sense of the use of cognitive systems and deep neural networks. Here, large parts of the content of legal decision-making are automated, e.g., by AI -assisted analysis of the content of files and subsequent autonomous generation of pleadings and decisions. Some of the systems can also (partially) replace legal work. In this context, artificial intelligence is to be understood in the sense of machine-understandable data, i.e., automatisms. Legal Tech 3.0 includes systems also located outside the judiciary, such as online air passenger portals, which initially perform automated checks free of charge to determine whether compensation is likely to be due for certain flights in the event of a cancellation or long delay. On this basis, a user can then instruct the respective provider online to enforce his claims against the airline on his behalf or to buy them directly from him. Other online platforms relate, for example, to reviews of rental claims. For example, the

7 Der Standard (Internet edition), 'Estland will Richter durch künstliche Intelligenz ersetzen' (Der Standard, 3 April 2019) <https://www.derstandard.at/story/20001006 13536/justiz-estland-will-richter-durch-kuenstliche-intelligenz-ersetzen> accessed 29 May 2021; Wissenschaftliche Dienste Deutscher Bundestag „Künstliche Intelligenz in der Justiz - Internationaler Überblick“ WD 7 -3000 -017/21,7 <https://www.bunde stag.de/resource/blob/832204/6813d064fab52e9b6d54cbbf5319cea3/WD-7-017-2 1-pdf-data.pdf $>$ accessed 29 May 2021; Lukas Staffler and Oliver Jany, 'Künstliche Intelligenz und Strafrechtspflege -eine Orientierung' (2020) 164 Zeitschrift für Internationale Strafrechtsdogmatik 170. <http://www.zis-online.com/dat/artikel/20 20_4_1357.pdf $>$ accessed 25 June 2021. 
German Federal Court of Justice (BGH) ruled in a basic decision dated April 8, 2020 (Ref.: VIII ZR 130/19) that the portal does not violate the statutory regulations, in particular the provisions of the Legal Services Act (RDG). Algorithms also check claims of people threatened with losing their jobs, the amount of accident payments or possibilities of appealing against social welfare notices.

\section{AI support for the judiciary and prosecution authorities}

In the following remarks, I will focus on AI support for the judiciary and prosecution authorities. This is because the judiciary faces a major challenge: Ordinary people without lawyer representation are often not able to use the system clearly or efficiently. They do not understand the legal system without outside help and often cannot afford specialized lawyers. For their part, in the face of an increasingly complex legal system, the courts face the problem that they are hardly able to efficiently process the huge amounts of legal norms, information and arguments in a quick manner, given a very difficult resource situation (financial constraints, too few judges due to budget cuts). Nevertheless, the expectations on the judiciary remain high. In particular, the judiciary is expected to use modern IT in a manner like institutions in civil society. In addition, the situation is exacerbated by the fact that large platforms operated by the private sector have managed to use data to bring enormous new volumes of cases into the court system. Debt collection agencies send AI enabled automated filings of cases against people for debt to the courts. Thus, AI tools are leading to a flood of cases into the courts, calling for the courts to also use the tools to manage this volume of applications and automatically evaluate the cases received. And finally, the pressure is also growing due to competition from private arbitration courts and mediation bodies, online dispute resolution platforms and automated decision-making, which can produce much faster decisions than the courts due to intensive AI use.

\subsection{Categories}

If one tries to catalog the AI under consideration for the judiciary, three main categories classification/analysis, translation/anonymization and interaction can be considered:

Classification and analysis involve the structuring of incoming documents: It is conceivable that documents received by the court can be analy- 
zed with artificial intelligence and assigned to different areas of law, such as criminal law, civil law, and labor law. In criminal cases, texts can be automatically differentiated into categories such as " interrogation of defendants", "statements of witnesses" or "criminal complaint". In this way, documents and parts of documents can be classified, at least provisionally, which in turn can relieve the judge in his decision-preparing activities.

\subsubsection{Information Retrieval, Data Extraction}

Within a document, in addition to the simple search functions used so far, certain content-related contexts can also be found, motions or requests for evidence can be filtered out and assigned to certain facts or legal arguments. This is a particularly useful tool when the data coming in with a document is unstructured. These possibilities for electronic analysis of specific data in larger data collections found its origin in so-called e-discovery in the context of electronic forensic data analysis, later also in criminal or administrative investigation proceedings. ${ }^{8}$ And content-related connections can also be made clear in pleadings, even if they cannot be recognized by a human without further effort. This is particularly helpful in mass proceedings, where it is necessary to find commonalities and possibly individual differences in the documents. Such tools could also be used to analyze the pleadings of litigants to determine the extent to which they relate to one another, where differences in content exist, where repetitions can be identified, and where redundancies can be eliminated.

Some active, intelligent AI based case management systems like the smart court management system of the Hebei High Court in China automatically scan and digitize filings, transfer documents into electronic files, match incoming documents to existing files, identify relevant laws, cases, and legal documents to be considered, automatically generate all necessary court procedural documents and distribute cases to judges for them to be put on the right track. ${ }^{9}$ In various courthouses, AI-equipped robots are also being used that can retrieve and communicate information on judges, court employees, procedural rules, and procedural actions. It is also possible to use AI to extract arguments from lawsuits and other

8 Jens Wagner, Legal Tech und Legal Robots (SpringerGabler2 $2^{\text {nd }}$ edn 2020) 43.

9 Jonah Wu, 'AI Goes to Court: The Growing Landscape of AI for Access to Justice' (Medium, 2019) <https://medium.com/legal-design-and-innovation/ai-goes-to-cou rt-the-growing-landscape-of-ai-for-access-to-justice-3f58aca4306f $>$ accessed 29 May 2021. 
motions and compare them to similar legal cases. In Brazil, an AI program called "Socrates" analyzes new incoming cases at the highest federal court in Brazil (Superior Tribunal de Justiça) for commonalities based on data from 300,000 closed cases and forms groups of similar cases, so that they can be judged in blocks. ${ }^{10}$ This program can also automatically review incoming appeal documents to gain knowledge regarding the jurisdiction of the court. Similarly, the Brazilian Constitutional Court (Supremo Tribunal Federal) has an AI program called "VICTOR" developed that can automatically analyze incoming cases for jurisdictional requirements for the court. ${ }^{11}$

\subsubsection{Automated analysis and statistical evaluation of sentencing considerations in criminal judgments.}

In Germany, a "Smart Sentencing Task Force" of the Legal Tech Lab Cologne ${ }^{12}$ is working on the automated analysis and statistical evaluation of sentencing considerations in criminal judgments. The aim is to create a publicly accessible database with a search function that will, for example, enable the criminal judge to find those decisions from a large number of judgments that are similar to the case to be decided by the judge. In addition, it will be possible to analyze the considerations that have an impact on the sentence level or to filter out, based on statistical material, what impact the presence of a certain characteristic has on the sentence level decision. ${ }^{13}$

AI-based systems that can predict decisions are also becoming increasingly important. On the one hand, this could be used to give the litigants better opportunities to formulate their arguments. This could possibly

10 Flavio Fereira, 'Artificial Intelligence Makes its Mark in the Brazilian Judicial System' (Folha de S.Paulo, 10 March 2020) <https://www1.folha.uol.com.br/inter nacional/en/brazil/2020/03/artificial-intelligence-makes-its-mark-in-the-brazilian-j udicial-system.shtml> accessed 31 May2021; Wissenschaftliche Dienste Deutscher Bundestag (n 7) 8.

11 Wissenschaftliche Dienste Deutscher Bundestag (n 7) 8; Daniel Becker and Isebela Ferrari, Artificial Intelligence and the Supreme Court of Brazil-Beauty or a Beast? (22 June 2020) $2<$ https://sifocc.org/app/uploads/2020/06/Victor-Beauty-or-the-Beast.p df $>$ accessed 31 May 2021.

12 Under the scientific direction of Prof. Rostalski, Chair of Criminal Law, Criminal Procedure Law, Philosophy of Law and Comparative Law at the University of Cologne $<$ https://legaltechcologne.de/smart-sentencing/> accessed 30 May 2021.

13 Isabell Biallaß (n 2) para 206. 
even be integrated into online court platforms to give potential plaintiffs a chance to have their legal options checked, for example at the legal application offices. On the other hand, it could also be used by judges to improve their decision preparation or, in extreme cases, even to install a robot judge.

In a study, the University College of London (UCL) explored the possibilities of predicting the outcome of proceedings before the European Court of Human Rights based on the decision text of 584 cases alone. ${ }^{14}$ The aim was to obtain a prediction as to whether there had been a violation of Art. 3, 6 or 8 of the European Convention on Human Rights. For this purpose, parts of the text that did not contain the decision were extracted from the judgments. The correct outcome of the proceedings was predicted with a 79 percent probability, which is not very high.

AI experts and lawyers in Australian Family Law have developed a split-up system based on neural networks to predict outcomes for property disputes in divorce and other family law cases. ${ }^{15}$ However, the Split-Up system is only used by judges to support their decision-making, by helping them to identify some relevant aspects that should be taken into account in maintenance or provision decisions. The system will above all present the proposals transparently to the judge.

Since court files are subject to a high degree of confidentiality and files on ongoing proceedings cannot, for the most part, be used as material for artificial intelligence programming, it is a particular challenge to extract learning material for artificial intelligence from court files.

14 Nikolaos Aletras, Dimitrios Tsarapatsanis, Daniel Preoțiuc-Pietro and Vasileios Lampos, 'Predicting judicial decisions of the European Court of Human Rights: a Natural Language Processing perspective' (PeerJ Computer Science 2016) <https:/ /peerj.com/articles/cs-93/> accessed 20 May 2021); Chris Johnston, 'Artificial intelligence judge developed by UCL computer scientists' (The Guardian, 29 October 2016)<https:/www.theguardian.com/technology/2016/oct/24/artificial-in telligence-judge-university-college-london-computer-scientists $>$ accessed 25 June 2021.

15 John Zeleznikow and Andrew Stranieri, 'Split Up: An Intelligent Decision Support System Which Provides Advice Upon Property Division Following Divorce'(1998) 6, 2 International Journal of Law and Information Technology 190213. 


\subsubsection{Use of AI for criminal investigative services to detect child pornography and child abuse.}

It can also be very useful for criminal investigative bodies to have cognitive systems technology for their work. Image, video, and audio material can be analyzed in an automated way to determine whether a person is visible and if so, which person, whether the person is a juvenile or older, which is potentially relevant for sexual criminal law, child pornography. Thus, on May 25, 2021, the Minister of Justice of North Rhine-Westphalia and the project partners presented a hybrid cloud scenario ZAC - AIRA ("AI enabled Rapid Assessment"), which is intended to revolutionize the work of public prosecutors. ${ }^{16}$ Together with Prof. Dr. Sorge and Prof. Dr. Brodowski (Saarland University), the AI specialist Dr. Krohn-Grimberghe, the German EDV- Gerichtstag and Microsoft as a business partner, ZAC NRW had developed an AI-based tool kit that can classify image material into the categories child pornography, juvenile pornography, non-criminal adult pornography and other image material with an accuracy beyond $90 \%$. The AI used is not intended to replace the human evaluator and the legal evaluator, but to help filter out quickly and effectively from a large amount of data at a very early stage of the investigation those pieces of evidence that are necessary to examine the urgent suspicion of the crime required for pre-trial detention.

In white-collar criminal cases, documents can be checked to see if a particular word is used that could be significant in further clarifying any criminal charges.

\subsubsection{Use of AI to categorize offenders}

In the United States, a software program developed by the company Equivant in 1998 with an algorithm called COMPAS (Correctional Offender Management Profiling for Alternative Sanctions) is used by criminal justice institutions to categorize offenders according to a risk score. This risk score calculates the probability of criminal recidivism. The calculated probability, in turn, is used to make decisions about sentence levels or possible early release from prison. The software obtains decision insights from

$16<$ https://www.sueddeutsche.de/panorama/justiz-duesseldorf-ergebnis-kuenstliche-i ntelligenz-erkennt-kinderpornografie-dpa.urn-newsml-dpa-com-20090101-210524 -99-725248> accessed 30 May 2021. 
court records and from answers to questions posed to the defendant. ${ }^{17}$ However, the use of this software has also revealed problems, as one study points out. For example, dark-skinned people were apparently assigned higher recidivism risks in principle than white people. Angwin/Larson/Mat$t u$ / Kirchner cite a case in which the computer program spat out a score predicting the likelihood of each committing a future crime. One person - who was black - was rated a high risk. Another person - who was white - was rated a low risk. Two years later, the computer algorithm got it exactly backward. The black person was not charged with any new crimes. The white man was serving an eight-year prison term for subsequently breaking into a warehouse and stealing thousands of dollars worth of electronics. This was not the only case where, in retrospect, the prognosis proved to be wrong. This was not the only case where, in retrospect, the prognosis proved to be wrong. The forecasts in the use of COMPAS were only 65 percent correct, far too low to be able to attach significant legal consequences to them. ${ }^{18}$

By using machine learning AI, there is a risk of a vicious circle: In a district that is frequently affected by burglaries, the police will increasingly patrol. As a result, more crimes will be detected there than elsewhere in the city. This, in turn, makes it necessary for the AI system to consider an even stronger police presence, which increases the described effect of crime detection and may lead to exclusion zones. People living there will then no longer be able to sign contracts or find jobs. And the fact that this person lives in such a district makes prognosis with such programmed AI to experience a future without committed crimes unfavorable. Something similar can happen with dark-skinned people, who are usually more and more suspected under the influence of AI. This risk of discrimination, which is inherent in the programming of $\mathrm{AI}$, must be considered when deploying AI.

Furthermore, with the help of artificial intelligence, the chronological events in a case, a historical description, i.e. a timeline, can be created.

17 Julia Angwin, Jeff Larson, Surya Mattu and Lauren Kirchner, 'Machine Bias. There's software used across the country to predict future criminals. And it's biased against blacks', (ProPublica, 23 May 2016) https://www.propublica.org/article/ma chine-bias-risk-assessments-in-criminal-sentencing accessed 25 June 2021.

18 Franziska Wahedi, Verfassungsrechtliche Anforderungen an die Automatisierung der Justiz, (Dr.Kovac 2021) 25 ff; Aleš Završnik, 'Criminal justice, artificial intelligence systems and human rights' (Springer 2020) <https://link.springer.com/articl e/10.1007/s12027-020-00602-0> accesssed 31 May 2021. 
Citations of standards or case law can be linked to standards and case databases, or citations can be checked for accuracy.

\subsubsection{Automated Translation}

Very useful could be the use of AI for translation in the field of justice. Especially in the European Union with 24 different official languages, it is often necessary to translate foreign-language texts into the court language in cross-border legal cases, which results in significant costs. Often, once translations are made, they are not reused for other proceedings. Professional translators today often work with machine translation programs and then adapt the automatic translation proposal to the requirements of the specific translation job. Or translators develop their own translation memories as patterns for specific text fragments. Neural machine translation is based on neural network modeling, which is modeled after the human brain. The neural machine learns from texts available in both languages, recognizes users and adapts further translations to these requirements. The German European Council Presidency in the 2nd half of 2020 had released a website - the EU Council "Presidency Translator"19 - and in this way kept various automatic translation programs available. It can be seen from the analysis that the different programs vary in terms of the subject area in which they are used.

\subsubsection{Anonymizing court judgments}

AI can also be used to anonymize court judgments. This is because it is sometimes not enough to just black out personal names to prevent rapid de-anonymization. AI may be able to use context analysis here to figure out what further anonymization needs to be done.

\subsubsection{Interaction}

Another category of application areas for AI is interaction. Online dispute resolution procedures already exist - outside the narrow scope of the judiciary - which largely automate the submission of requests and the responses 
of the dispute resolution body. ${ }^{20}$ However, since they do not generally produce binding decisions automatically, their use is not yet problematic unless they increasingly take the place of the judiciary. Newer forms of legal action such as the "Musterfeststellungsklage" are also based on - at least simple forms of - artificial intelligence.

In countries as the UK and in provinces in China, there is a noticeable tendency to virtualize processes, although not to automate all steps. In Germany, a working group on "Modernization of Civil Procedure" has drawn up proposals for the judiciary on behalf of the presidents of the Higher Regional Courts, the Court of Appeal, the Bavarian Supreme Regional Court and the Federal Court of Justice ${ }^{21}$ : According to these proposals, an accelerated online procedure in the form of a form-based procedure is to be introduced, which as a rule is to be conducted entirely by means of electronic communication. It can be concentrated at certain courts and is to be introduced for amounts in dispute up to $€ 5,000$. The first consideration here is mass disputes between consumers and defendant companies, but a later expansion could be considered. Such an accelerated online procedure will also be accompanied by the introduction of automated mechanisms, again relying on AI.

Theoretically, AI is also capable of automatically generating decision documents. First, so-called legal generators are created which, after the facts of the case have been entered, perform a subsumption under the legal norm. In its simplest form, this is already done by electronic fee and deadline calculators or - as already illustrated - in the process of creating automatic payment orders. Such subsumptions can be prepared by means of dynamic electronic forms or questionnaires, which in turn are linked to a programmed legal result, as is already happening with the online platforms for checking any claims for flight delays.. ${ }^{22}$ Finally, documents - decisions - possibly also with justifications are automatically produced from the found legal result.

Since tools already exist that are used, for example, by online arbitration boards which automatically produce certain decision proposals, it is also technically conceivable to fully automate processes.

However, this is currently not planned, at least in Germany. It is true that in administrative proceedings it is possible to issue a so-called automa-

20 Franziska Wahedi (n 18) $178-179$

$21<$ https://www.justiz.bayern.de/media/images/behoerden-und-gerichte/oberlandesg erichte/nuernberg/thesenpapier_der_arbeitsgruppe.pdf $>$ accessed 25 June 2021.

22 Jens Wagner (n 8). 47. 
tic administrative act - provided there is no discretion or scope for assessment on the part of the authority, see $\$ 35$ a Administrative Procedure Act. However, the court decision is not comparable to an administrative decision. There are legal remedies against an automatic administrative act that people decide on. But who decides on automatic court decisions?

There is only sparse discussion in Germany about whether a parallel provision to $\$ 35 \mathrm{a}$ VwVfG (Administrative Procedure Act) should be created for court decisions. If one takes up the basic idea of $\$ 35 \mathrm{a} \mathrm{VWfG}$, then an automatic decision only comes into consideration in very strongly structured procedures such as the order for payment procedures or the small claims procedures, i.e. in the enforcement of minor claims, if a decision is already based only on formal criteria. Politicians, such as the German Conference of Ministers of Justice, decided against such automatic court decisions.

\subsubsection{Further possibilities of AI use in the judiciary}

Chatbots based on artificial intelligence could also be used. ${ }^{23}$ In this way, applications or responses to complaints could be recorded in a structured manner via information systems, thus relieving or replacing the lawyers' offices. Attorney applications could be checked for conclusiveness by chatbots.

\subsection{Use of AI by the European Union}

The outlined use scenarios for AI in the judiciary have also attracted the attention of the European Union. The new multi-annual action plan for EJUSTICE 2019-2023 adopted in December $2018^{24}$ provides the following:

One project aims to define "the role that AI could play in the field of justice and to develop an AI tool for the analysis of court decisions." Another project is planned to develop a chatbot for the E-JUSTICE portal "that will assist users and guide them to the information they are looking for". Of course, these EU projects do not cover all possible scenarios for the use of artificial intelligence in the judiciary. But it is a first step.

23 Franziska Wahedi (n 18) $77 \mathrm{ff}$.

24 OJ 2019/C 96/05. 


\section{Legal assessment of the use of artificial intelligence in the judiciary}

\subsection{GDPR}

Incidentally, within the scope of application of the GDPR of April 2016 25 , with Europe-wide validity, Art. 22 (1) GDPR standardizes that a data subject has a right to action by a human being, a machine decision is not sufficient - unless the data subject has consented to such an automatic decision or national law provides otherwise.

\subsection{Principles of national constitutions, European Charter of Fundamental Rights, Universal Declaration of Human Rights (United Nations), International Covenant on Civil and Political Rights}

In any case, some principles must be observed laid down in national constitutions, but also in supranational law such as the European Charter of Fundamental Rights. The Universal Declaration of Human Rights proclaimed by the United Nations General Assembly on 10 December 1948 is not a treaty, so it does not directly create legal obligations for countries. Because countries have consistently invoked the Declaration for more than sixty years, it has become binding as a part of customary international law and has given rise to a range of other international agreements like the International Covenant on Civil and Political Rights (ICCPR) which are legally binding on the countries that ratify them. In particular, the obligations of each State Party to the Covenant mentioned in Article 2 are significant in this context: "undertakes to respect and to ensure to all individuals within its territory and subject to its jurisdiction the rights recognized in the present Covenant, without distinction of any kind, such as race, colour, sex, language, religion, political or other opinion, national or social origin, property, birth or other status". "Each State Party to the present Covenant undertakes: (...) (b) to ensure that any person claiming such a remedy shall have his right thereto determined by competent judicial, administrative or legislative authorities, or by any other competent authority provided for by the legal system of the State, and to develop the

25 Regulation (EU) 2016/679 of the European Parliament and of the Council of 27 April 2016 on the protection of natural persons with regard to the processing of personal data and on the free movement of such data and repealing Directive 95/46/EC [2016] OJ L119/89 (General Data Protection Regulation). 
possibilities of judicial remedy; (c) To ensure that the competent authorities shall enforce such remedies when granted."

\subsubsection{Constitutional principles that suggest the use of artificial intelligence}

There are constitutional principles that suggest the use of artificial intelligence in certain cases.

For example, it follows from national constitutional law (Article 19 (4) of the German Basic Law) that effective legal protection must be guaranteed. This includes the guarantee of legal protection within a reasonable time, which is based on the specific circumstances of the case. If courts are unable to provide legal protection within a reasonable period due to inadequate equipment, technical means must also be used to increase efficiency. The aspect of the judiciary's ability to function (Article 20 (3) of the German Constitution) must also be considered. It also dictates that information technology tools should not be denied to the judiciary if this is the only way to maintain its ability to function.

\subsubsection{Principles that could oppose the use of AI}

On the other hand, however, constitutional principles must also be considered that could oppose the use of AI in individual cases:

(1) Right to human dignity

Above all, the right to human dignity must be observed. ${ }^{26}$ In conjunction with Article 2 (1) of the German Basic Law, this gives rise to the right to protection of personality, the right to informational self-determination, which has been given its own form in Article 7 of the European Charter of Fundamental Rights in the form of the right to determine the use of information about one's personal life.

26 Art. 1 para. 1 German Basic Law, Art. 1 European Charter of Fundamental Rights, Art. 2 sentence 1 TEU, Art. 1 of the Universal Declaration of Human Rights of the United Nations of 10.12.1948. 
(2) Principle of non-discrimination

The obligation to observe the principle of equality and the principle of non-discrimination ${ }^{27}$ has already been pointed out. Caution is required if judges use software for their decision whose programming is not disclosed and therefore discriminatory input - as in the case of the COMPAS software - is not visible to the judge. The transparency requirement also follows from the principle of the rule of law (Article 20 of the German Basic Law).

\section{(3) Principle of the natural and independent judge}

It is established the guiding principle of the natural judge (according to Art. 92 German Basic Law), the independent judge, who must at all times retain control over his own decision, i.e. must not leave it to a self-learning machine, the result of which no one can foresee or concretely influence. The judge, when using IT assistance software, to be able to recognize which data material has been used, in order to be able to make his or her own, responsible, and if necessary to be able to make a decision that will further develop the law. ${ }^{28}$

Art. 10 Universal Declaration of Human Right ${ }^{29}$ can also only be understood in such a way that the independent judge cannot mean a machine programmed by technicians.

\section{(4) The right to an effective remedy}

The right to an effective remedy implies the right to a reasoned and individual decision. Article 13 of the European Convention on Human Rights: "Everyone whose rights and freedoms as set forth in this Conventi-

27 Art. 3(1) sentence 1 German Basic Law; Art. 20, 21 European Charter of Fundamental Rights, Art. 9 TEU, Art. 14 European Convention on Human Rights, Art. 2 United Nations Universal Declaration of Human Rights.

28 Wilfried Bernhardt and Christina-Maria Leeb, 'Elektronischer Rechtsverkehr' in Dirk Heckmann and Anne Paschke (ed) jurisPK-Internetrecht 7th edition, chapter 6 (status: 01 June2021), para 860.

29 "Everyone is entitled in full equality to a fair and public hearing by an independent and impartial tribunal, in the determination of his rights and obligations and of any criminal charge against him.” 
on are violated shall have an effective remedy before a national authority (...)" The Study on the Human Rights Dimensions of Automated Data Processing Techniques ${ }^{30}$ rightly emphasizes: "Automated decision-making processes lend themselves to particular challenges for individuals' ability to obtain effective remedy. These include the opaqueness of the decision itself, its basis, and whether the individuals have consented to the use of their data in making this decision or are even aware of the decision affecting them. The difficulty in assigning responsibility for the decision also complicates individuals' understanding of whom to turn to address the decision. The nature of decisions being made automatic, without or with little human input, and with a primacy placed on efficiency rather than human-contextual thinking, means that there is an even larger burden on the organisations employing such systems to provide affected individuals with a way to obtain remedy."

\section{(5) Fair trial}

The requirement of a fair trial (Art. 47 para. 2 European Charter of Fundamental Rights, Art. 6 European Convention on Human Rights) gives the parties to the proceedings the opportunity to influence the course and outcome of the proceedings. This, too, is likely to be difficult to realize in the case of a self-learning, unsupervised AI. Also Art. 14 ICCPR (...” everyone shall be entitled to a fair and public hearing by a competent, independent and impartial tribunal established by law") reveals the essential obligations that are difficult to fulfill by a machine.

(6) Right to the legal judge

In addition, the right to the legal judge requires that certain responsibilities be observed and that the competent judge or court panel be clearly determined before the dispute begins. But who is responsible for a machine deciding a case? The question of legal responsibility is a core issue in

30 Committee of Experts on Internet Intermediaries (MSI-NET), Study on the Human Rights Dimensions of Automated Data Processing Techniques (in Particular Algorithms) and Possible Regulatory Implications (6 October 2017) 23, <https://r m.coe.int/study-hr-dimension-of-automated-data-processing-incl-algorithms/16807 5b94a $>$ accessed 31 May 2021; Aleš Završnik (n 18). 
the use of artificial intelligence. Generally, the question is asked: Who is responsible for artificially intelligent, self-controlling machines? The buyer or owner of the robot that caused the damage? The manufacturer? The robot itself? Translated into the world of courts, this means: Who is then responsible for the court decision? The program manufacturer for the automatic court decision? The judiciary that provided for the use of the program? The court/judge that specifically arranged for the use of the program? Or the machine itself?

\section{(7) Transparency principle}

The verifiability of the decision in the sense of effective legal protection also suffers when a non-transparently operating machine decides. The transparency requirement follows from the principle of the rule of law. ${ }^{31}$ Thus, the already known dangers of discrimination must be considered, which can always occur when an AI takes existing discrimination as inventory data as a reason to perpetuate discrimination in the future.

(8) Principle of the right to be heard

Furthermore, the principle of the right to be heard (Art. 103 German Basic Law) as well as effective legal protection with the right to inspect the documents on which the judicial decision is based must be observed: For example, the use of AI could lead to the right to be heard running dry because certain bases for the decision are not known either to the litigants or to the court because the results of the AI use remain untransparent.

Care must be taken if the programming of the AI may have incorporated values from other legal systems that are inconsistent with the fundamental values of the European Constitutions and European specifications.

31 Franziska Wahedi (n 18) 40 et seq.; Jürgen Bröhmer, Transparenz als Verfassungsprinzip ( Mohr Siebeck 2004) $147 \mathrm{ff}$. 


\section{European Commission for the Efficiency of Justice}

2018 the European Commission for the Efficiency of Justice adopted certain principles that must also be observed for AI support. ${ }^{32}$ Accordingly, the following basic principles must be observed:

The design and implementation of AI tools and services must be compatible with human rights as laid down in the European Convention on Human Rights (ECHR) and in the Council of Europe Convention for the Protection of Personal Data. The development or intensification of any discrimination between individuals or groups of individuals must be prevented. Judicial institutions should be able to develop an understanding of data processing methods. External expertise should be brought in, and the use of certification systems with short certification intervals would also be useful. AI users should be informed and maintain control over their decisions. The judge should also always feel responsible for his decision. He should always have access to the data on which the decision is based. And he should always have the option to withdraw from the solution proposed by the AI, taking into account the specifics of the case.

\section{Proposal for a Regulation laying down harmonized rules on artificial intelligence.}

On April 21, the EU Commission presented the Proposal for a Regulation laying down harmonized rules on artificial intelligence. ${ }^{33}$ The proposal is "based on EU values and fundamental rights and aims to give people and other users the confidence to embrace AI-based solutions, while encouraging businesses to develop them. AI should be a tool for people and be a force for good in society with the ultimate aim of increasing human well-being. Rules for AI available in the Union market or otherwise affec-

32 European Commission for the Efficiency of Justice (CEPEJ), European ethical Charter on the use of Artificial Intelligence in judicial systems and their environment $<$ https://rm.coe.int/ethical-charter-en-for-publication-4-december-2018/16808f699 c> accessed 31 May 2021. See also the report on the CEPEJ Conference "Artificial intelligence at the service of the Judiciary"(27 September 2018) <https://www.coe. int/en/web/cepej/justice-of-the-future-predictive-justice-and-artificial-intelligence> accessed 31 May 2021.

$33 \operatorname{COM}(2021) 206$ final; <https://digital-strategy.ec.europa.eu/en/library/proposal-r egulation-laying-down-harmonised-rules-artificial-intelligence $>$ accessed 30 May 2021. 
ting people in the Union should therefore be human centric, so that people can trust that the technology is used in a way that is safe and compliant with the law, including the respect of fundamental rights (...) The proposal sets harmonized rules for the development, placement on the market and use of AI systems in the Union following a proportionate risk-based approach". The aim of this proposed regulation is to improve and promote the protection of the rights protected by the EU Charter of Fundamental Rights: ${ }^{34}$ the right to human dignity (Art. 1), respect for private life and the protection of personal data (Arts. 7 and 8), the prohibition of discrimination (Art. 21), and equality between women and men (Art. 23). The intention is to prevent interference with the rights to freedom of expression (Art.11) and freedom of assembly (Art 12). It also seeks to ensure protection of the right to an effective remedy and to a fair trial, the rights of the defense and the presumption of innocence (Arts. 47 and 48), and the general principle of good administration. The proposed regulation provides harmonized rules for the development, placing on the market, and use of AI systems in the Union using a risk-based approach. Particularly harmful AI practices will be banned for violating Union values. AI technologies with "high risk" that pose significant threats to the health and safety or fundamental rights of individuals can only be approved if they meet the requirements for trustworthy AI, if providers present a risk assessment and intended safeguards, and if they have undergone a review process with quality management and conformity assessment procedures (Art. 17) before they can be placed on the Union market and ensure the establishment, implementation and maintenance of a post-market surveillance system. ${ }^{35}$

The Proposed Regulation also comments on the use of a remote biometric recognition system "in real time" in publicly accessible premises for law enforcement purposes. ${ }^{36}$ "This should be subject to an explicit and specific authorization by a judicial authority or an independent administrative authority of a Member State, to be obtained in principle before use." However, in a duly justified urgent situation, the use of the system may start without authorization, and the authorization may be requested only during or after the use.

Recital 40 mentions AI systems intended for the administration of justice and democratic processes. These "should be classified as high-risk, considering their potentially significant impact on democracy, rule of law,

34 3.5. of the Explanatory Memorandum of the proposed regulation.

35 In detail Art. 8 et seq. of the proposed regulation.

36 Recital 21. 
individual freedoms as well as the right to an effective remedy and to a fair trial." Given the "risks of potential bias, error, and opacity," "AI systems intended to assist judicial authorities in researching and interpreting facts and law, and in applying the law to a specific set of facts" should be classified as high-risk. But - according to the proposed regulation - this classification does not extend to" purely ancillary administrative activities " with no impact on "the actual administration of justice in individual cases, such as anonymization or pseudonymization of judicial decisions, documents or data, communication between personnel, administrative tasks or allocation of resources".

The use of high-risk AI systems (when used, for example, in the administration of justice) require effective "human oversight" under Article 14. This means that judges, for example, would need to be aware of the possible tendency to automatically rely or over-rely on the output generated by a high-risk AI system ("automation bias"), especially when AI is used to provide information or recommendations for decisions. Such "human oversight" would also need to be able to " to correctly interpret the highrisk AI system's output, taking into account in particular the characteristics of the system and the interpretation tools and methods available. ${ }^{37} \mathrm{As}$ a consequence, the "human" must then also be able to not use the high-risk AI system or otherwise ignore, override, or reverse the output of the highrisk AI system.

\section{Conclusion}

The planned European AI Regulation is likely to oppose automatic court decisions (robot judges) using artificial intelligence, especially if such court decisions are beyond human control. This can also be derived from the German constitution. It is therefore unrealistic to expect the establishment of robot judges in the foreseeable future. ${ }^{38}$

However, the planned AI regulation is not only aimed at automatic decision-making systems of the judiciary, but also at AI systems for the preparation of decisions by judges. Thus, transparency about the risks

37 Art. 14 para 4 (c) of the draft.

38 Cancio Fernández, 'La sustitución directa de la actividad humana en la decisión judicial, al día de hoy, es puramente quimérica a corto y medio plazo' (Legal today, 11 September2020) <https://www.legaltoday.com/legaltech/nuevas-tecnol ogias/la-realidad-y-el-deseo-inteligencia-artificial-y-decision-judicial-2020-09-11/> accessed 31 May 2021. 
of AI must be established in this respect as well. Judges should not be allowed to rely rashly on the decision proposals; rather, they should use AI responsibly and also be able to "switch it off" once in a while.

But even if AI systems only support the courts, caution is required because - as explained - AI systems can reinforce discriminatory evaluations. Judges must therefore handle the systems with responsibility. The training and continuing education of judges must also enable them to do so. ${ }^{39}$

Nevertheless, the discussions surrounding the "robot judge" must not obscure the fact that AI can also provide valuable support in the judiciary - for example, in the areas of classification/analysis, translation and anonymization - which should not be dispensed with in view of the increasingly complex legal system, competition from online platforms and the scarcity of judicial resources.

39 UNESCO and partners are developing the program for capacity building of judicial actors concerning the use of AI in courts and by law enforcement, as well as to address the legal implications of AI judicial decisions based on international human rights standards: UNESCO, AI and the Rule of Law: Capacity Building for Judicial Systems <https://en.unesco.org/artificial-intelligence/mooc-judges> accessed 31 May 2021. 
